See discussions, stats, and author profiles for this publication at: https://www.researchgate.net/publication/320888594

\title{
Modelling the fate of PAH added with composts in amended soil according to the origin of the exogenous organic matter
}

Article in Science of The Total Environment · October 2017

DOl: 10.1016/j.scitotenv.2017.10.269

\section{CITATIONS}

5 authors, including:

\section{Khaled Brimo}

Institut de Radioprotection et de Sûreté Nucléaire (IRSN)

7 PUBLICATIONS 21 CITATIONS

SEE PROFILE

Sabine HOUOT

French National Institute for Agricultural Research

259 PUBLICATIONS 4,012 CITATIONS

SEE PROFILE

Some of the authors of this publication are also working on these related projects:

PRO-EXTERN View project

Project Carbon and nitrogen dynamics in soils View project
84

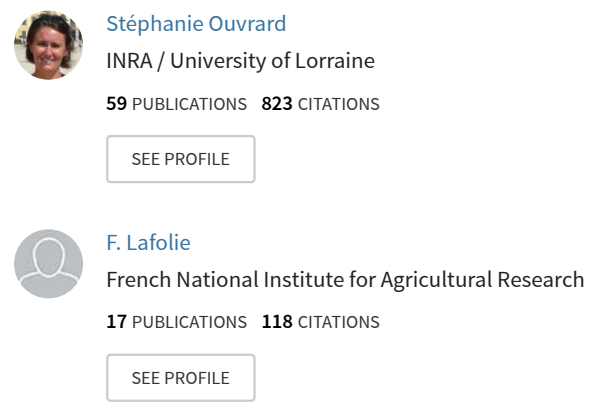




\title{
Modelling the fate of PAH added with composts in amended soil according to the origin of the exogenous organic matter
}

\author{
Khaled Brimo a,b,c , Stéphanie Ouvrard ${ }^{\text {b }}$, Sabine Houot ${ }^{a}$, François Lafolie ${ }^{\mathrm{d}}$, Patricia Garnier ${ }^{\mathrm{a}, *}$ \\ a UMR EcoSys, INRA, AgroParisTech, Université Paris-Saclay, 78850 Thiverval-Grignon, France \\ ${ }^{\mathrm{b}}$ UMR Laboratoire Sols et Environnement, INRA, Université de Lorraine, 54518 Vandoeuvre-lès-Nancy, France \\ ' Agence de l'Environnement et de la Maîtrise de l'Energie, 20 avenue du Grésillé, BP 90406, F-49004 Angers Cedex 01, France \\ 'UMR EMMAH, INRA, UAPV, 84914 Avignon 9, France
}

\section{H I G H L I G H T S}

- The model simulates the release of PAH from compost in soil according to organic carbon degradation.

- Processes that occur before compost application to the soil influenced the fate of PAHs in the soil.

- The PAH dissipation was higher in incubations of mature composts.

- The PAH dissipation was higher in incubations of soil amended with nonmature composts.

- The model calculates the proportion of biogenic and physically bound residues of PAHs.
G R A P H I C A L A B S T R A C T

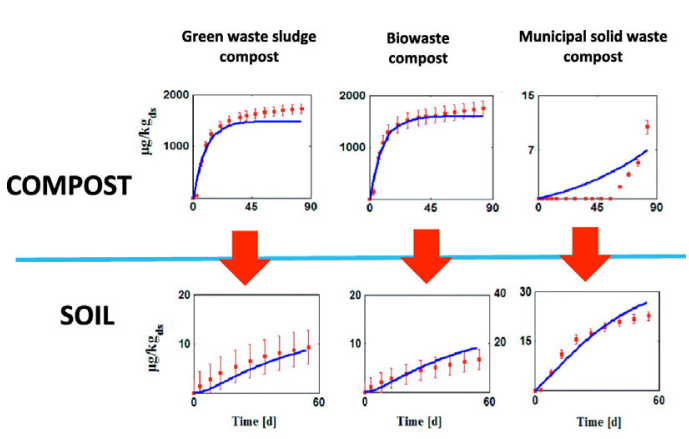

Mineralization of Phenanthrene

\section{A R T I C L E I N F O}

\section{Article history:}

Received 21 July 2017

Received in revised form 25 October 2017

Accepted 26 October 2017

Available online xxxx

Editor: Kevin V. Thomas

\section{Keywords:}

Polycyclic aromatic hydrocarbon

Model

Soil

Compost

Bounded residue

Bayesian approach

\begin{abstract}
A B S T R A C T
A new model that was able to simulate the behaviours of polycyclic aromatic hydrocarbons (PAH) during composting and after the addition of the composts to agricultural soil is presented here. This model associates modules that describe the physical, biological and biochemical processes involved in PAH dynamics in soils, along with a module describing the compost degradation resulting in PAH release. The model was calibrated from laboratory incubations using three ${ }^{14} \mathrm{C}$-PAHs, phenanthrene, fluoranthene and benzo(a)pyrene, and three different composts consisting of two mature and one non-mature composts. First, the labelled PAHs were added to the compost over 28 days, and spiked composts were then added to the soil over 55 days. The model calculates the proportion of biogenic and physically bound residues in the non-extractable compartment of PAHs at the end of the compost incubation to feed the initial conditions of the model for soil amended with composts. For most of the treatments, a single parameter set enabled to simulate the observed dynamics of PAHs adequately for all the amended soil treatments using a Bayesian approach. However, for fluoranthene, different parameters that were able to simulate the growth of a specific microbial biomass had to be considered for mature compost. Processes that occurred before the compost application to the soil strongly influenced the fate of PAHs in the soil. Our results showed that the PAH dissipation during compost incubation was higher in mature composts because of the higher specific microbial activity, while the PAH dissipation in amended soil was higher in the non-mature compost because of the higher availability of PAHs and the higher co-metabolic microbial activity.
\end{abstract}

(c) 2017 Elsevier B.V. All rights reserved.

\footnotetext{
* Corresponding author.

E-mail address: patricia.garnier@inra.fr (P. Garnier).
} 


\section{Introduction}

The recycling of composted organic residues in soils is a practice that is increasingly used in agriculture. It helps to prevent the loss of soil fertility by restoring soil organic matter contents as well as improving soil physical properties (Annabi et al., 2011; Goss et al., 2013; Mohammed et al., 2016; Tejada et al., 2009). However, certain organic pollutants, among them polycyclic aromatic hydrocarbons (PAH), may be present in the feedstock materials of these composts, leading to a soil contamination risk when they are recycled in agricultural areas (Brändli et al., 2005; Wilcke, 2000; Wild et al., 1991). It is of special importance to understand the dissipation of PAH that is added to soils with composted organic residues.

A number of studies have addressed the impact of compost applications on PAH-contaminated soils (as Puglisi et al., 2007; Zhang et al., 2012). They reported that compost application promotes both the formation of sequestered fractions of PAHs and its biodegradation, leading to the reduction of its concentration in contaminated soils. However only a few studies have addressed the fate of PAH when added to agricultural soils in composts (Haudin et al., 2013; Kästner et al., 1999). Haudin et al. (2013) studied the application of green waste and sludge compost containing different spiked ${ }^{14} \mathrm{C}$-organic pollutants (and among them one PAH molecule, fluoranthene) on their fates in soil. They found that their dynamic in soil depended on the pollutant properties but also on its distribution between the available and nonavailable fractions in the composts that enter the soil. Little is known about the impact of the composting process and the final quality of composts on the fate of PAHs in soil according to their physico-chemical properties.

A number of models have been developed to explore the fates of organic pollutants in amended soils (e.g., Morais et al., 2013; Wu et al., 2013; Zarfl et al., 2009), but models that consider the impacts of organic matter decomposition on the sorption and degradation of the pollutants explicitly are very scarce. Lashermes et al. (2013) simulated the mineralization of four organic pollutants during the composting of green waste and sludge. Geng et al. (2015) simulated the mineralization of these four organic pollutants after their incorporation with compost into the soil. Both studies show the broad interest in simulating the explicit interactions between pollutants and organic matter in models. The impact of the composting process and the type of composted organic matter on the organic pollutant's fate after its addition to the soil has never been simulated.

The aims of the present work were threefold: (i) use an experimental approach to study the impact of the compost quality (for three composts consisting of green waste and sludge compost, biowaste compost, and municipal solid waste compost) on the fate of PAHs in composts and after compost applications to soil for three different ${ }^{14} \mathrm{C}$-labeled PAHs (phenanthrene, PHE, fluoranthene, FLT and benzo(a)pyrene, BAP), (ii) propose a new coupled model to study the dynamics of PAHs in soil-compost mixture systems that explicitly accounts for the type of organic amendments on the fate of the PAHs during the decomposition of compost in the soil and (iii) calibrate the model with the experimental data and compare the kinetics of mineralization and dissipation for each PAH according to the compost quality.

\section{Modelling}

\subsection{Model description}

\subsubsection{General structure}

The PAH model is made of the following 3 modules: a PAH biodegradation/adsorption module, an OC (organic carbon) module and a PAH release module (Fig. 1 and Table A1). The structure of the PAH biodegradation/adsorption module is based on the model described by Brimo et al. (2016). The specific module of the OC dynamic and its interaction with the PAH module were added according to the models developed in
Lashermes et al. (2013) and Geng et al. (2015) that simulate the interactions between organic matter and organic pollutant (such as PAHs) dynamics during composting and after compost application to the soil. The novelty of our model here is that we add a PAH release module to simulate the release of PAHs from compost into soil during the decomposition of the compost.

The PAH biodegradation/adsorption module associated with the $\mathrm{OC}$ module is able to simulate the fate of PAH dynamics during compost incubation. The PAH biodegradation/adsorption module alone is able to simulate the PAH dynamic in soil without compost, and the 3 modules together are built to simulate the PAH dynamic in soils amended with compost.

In our previous model described in Brimo et al. (2016) the biological and chemical mechanisms controlling PAH behaviours in soil are modelled using two sub-modules as shown in Fig. 1: the adsorption module and the biodegradation module. The adsorption module is based on a bi-phasic first-order kinetic model with an initial fast kinetics characterized by weak sorption $\left(\mathrm{PAH}_{\mathrm{WS}}\right.$, where "ws" refers to weakly sorbed), and a slower kinetics with strong sorption ( $\mathrm{PAH}_{\mathrm{SS}}$, where "ss" refers to strongly sorbed). The biodegradation module assumes that biodegradation uses only the soluble $\mathrm{PAH}\left(\mathrm{PAH}_{\mathrm{AV}}\right.$, where "av" refers to available) with specific degradation pathways from a specific microbial biomass $\left(\mathrm{B}_{\mathrm{SPE}}\right.$ ) whose growth and maintenance is described by the Monod equation (as indicated by dotted lines in Fig. 1) and cometabolic degradation pathways modelled using second-order kinetics from the microbial biomass that degraded the compost $\left(\mathrm{X}_{\mathrm{cp}}\right)$ (dashed lines in Fig. 1). The degradation of $\mathrm{PAH}$ produces $\mathrm{CO}_{2}$ emissions $\left(\mathrm{PAH}_{\mathrm{CO} 2}\right)$, metabolites $\left(\mathrm{PAH}_{\mathrm{MET}}\right)$, and biogenic non-extractible residues $\left(\mathrm{PAH}_{\mathrm{BS}}\right)$. The influences of the temperature and the water content on the biological processes are taken into account using the correction factors $\mathrm{f}_{\mathrm{T}}$ and $\mathrm{f}_{\mathrm{W}}$ for the temperature and the water content, respectively (see Table A1 in SI).

The OC dynamic module was based on the modules proposed by Lashermes et al. (2013) and Geng et al. (2015), which describe organic matter transformations during composting and during compost decomposition in soil, respectively. The organic carbon in the compost was divided into several pools that were measured using the Van Soest fractionation method and characterized by their specific degradability. All the organic pools are hydrolysed into available substrates (DOC) for the growth of the compost-degrading microbial biomass $\left(\mathrm{X}_{\mathrm{cp}}\right)$ according to their specific hydrolysis constants. The microorganisms die at a specific death rate and the dead cells are recycled into either the compost organic compartment $\mathrm{SND}_{\text {slow }}$ (with slow degradation rate) or directly into the DOC compartment. Humified organic C (HOC) was assumed to be derived from dead microbial biomass to simulate the "Soil" condition, while for the "compost" condition, this part of the model is not activated and all the dead biomass is recycled. The PAHs available in the $\mathrm{PAH}_{\mathrm{AV}}$ solution (as calculated in the PAH module) can be degraded through co-metabolism by microorganisms $\mathrm{X}_{\mathrm{cp}}$ that use the compost organic matter as their primary energy source (as calculated in the OC module). We assumed that the contribution of $\mathrm{PAH}_{\mathrm{AV}}$ to $\mathrm{X}_{\mathrm{cp}}$ growth and maintenance can be neglected because $\mathrm{PAH}_{\mathrm{AV}}$ has low concentrations of PAH compared to the total quantity of organic carbon substrates in the compost. The evolution of the microbial biomass in a soil-compost mixture system is essentially driven by the decomposition of the fresh organic matter that is added with the compost (see explanations in SI 1).

A new PAH Release module was developed in this study to describe the release of the PAHs contained in compost during the decomposition of the compost that was applied to the soil. This module is used only for amended soil incubations and not for composting incubations. The $\mathrm{PAH}_{\mathrm{CPWS}}$ (where "cpws" refers to PAHs that are weakly sorbed onto organic carbon pools of compost) is subject to dual processes (Fig. 1). We assumed that the $\mathrm{PAH}$ is distributed among the OC fractions proportionally to the relative mass of each fraction. One fraction of PAH moves into the soil solution $\left(\mathrm{PAH}_{\mathrm{AV}}\right)$, with the hydrolysis of organic pools of 


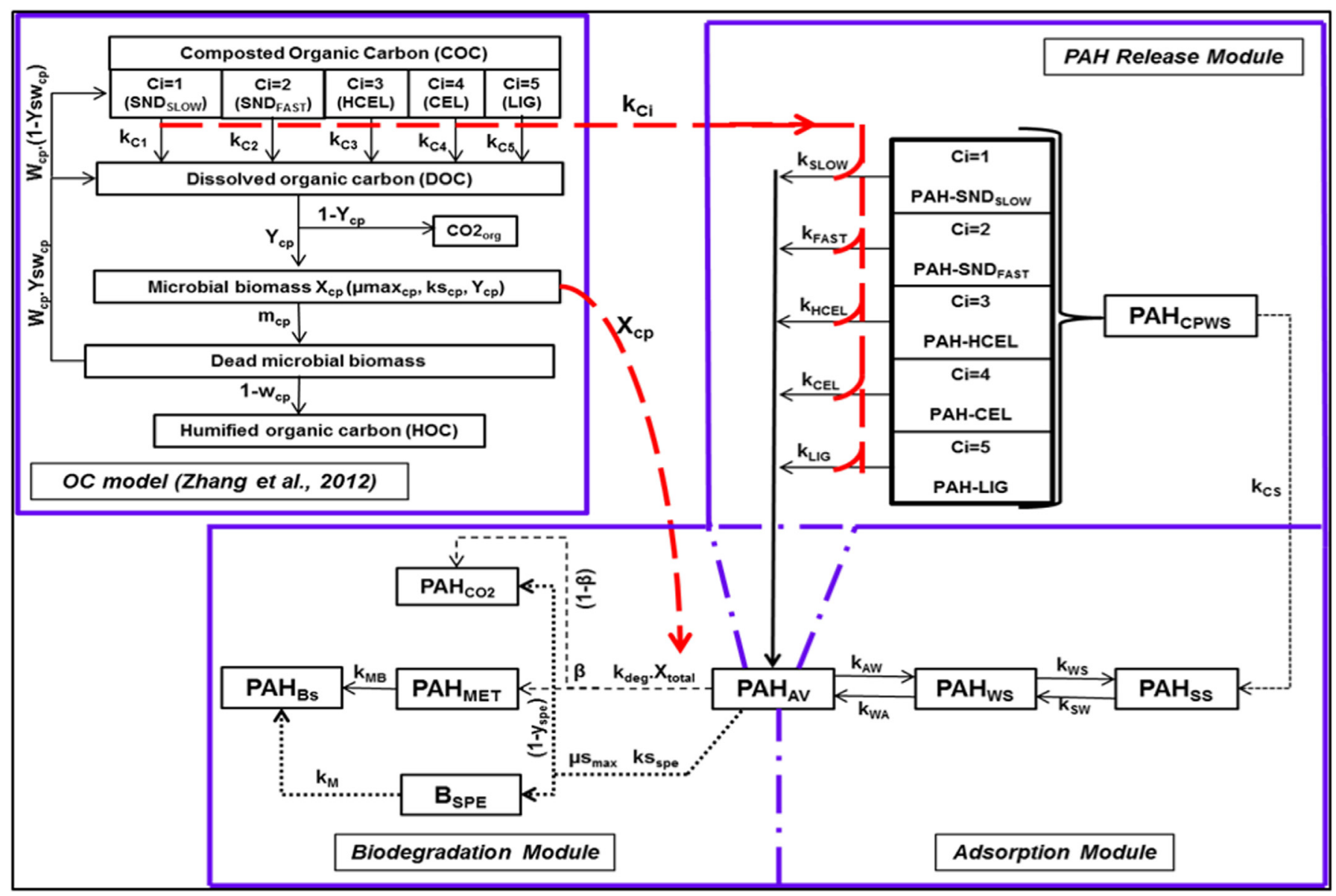

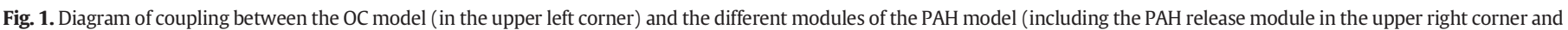

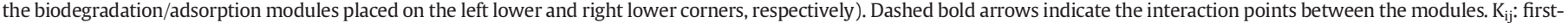

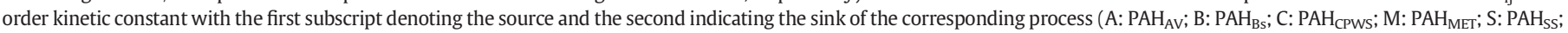

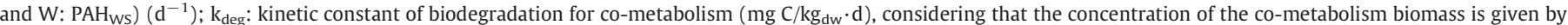

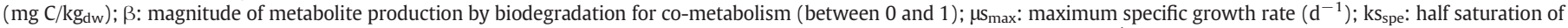
the growth substrate for the specific biomass $\left(\mathrm{mg} \mathrm{C} / \mathrm{kg}_{\mathrm{dw}}\right) ; \mathrm{Y}_{\text {spe }}$ : yield of specific biomass $(-)$; and $\mathrm{k}_{\mathrm{M}}$ : mortality rate constant $\left(\mathrm{d}^{-1}\right)$.

compost set to become an available substrate for the microorganisms (Processes XI, XII, XIII, XIV, and XV in Table A1). We assume that the $\mathrm{PAH}$ release rates into the solution are proportional to the hydrolysis of the compost pool to which they belong because PAHs are closely associated with the organic carbon pools of compost. For simplicity, we assume the irreversibility of this process. The other fraction of $\mathrm{PAH}$ becomes much more strongly sorbed onto the surface of the soilcompost mixture (process IV in Table A1) and goes directly from the $\mathrm{PAH}_{\mathrm{CPWS}}$ of the compost compartment into the $\mathrm{PAH}_{\mathrm{SS}}$ soil compartment. This process was simulated because the experimental results described below show high bound residue formation in some treatments in spite of the low organic matter decomposition and then the low PAH release by hydrolysis.

The release rate of $\mathrm{PAH}_{\mathrm{CPWS}}\left(\mu \mathrm{g} / \mathrm{kg}_{\mathrm{ds}}\right)$ that was added with compost as a function of the organic pool hydrolysis kinetics is calculated using Eq. (1) as follows:

$\frac{d P A H_{C P W S}}{d t}=-\Sigma_{i=1}^{i=5}\left[\frac{\left(k_{C i} \cdot C_{i, t}-f_{i, t}\right) \cdot f_{C i}}{\sum_{i=1}^{i=5} C_{i, t}} \cdot P A H_{C P W S}\right]-k_{C S} \cdot P A H_{C P W S}$

$\mathrm{C}_{\mathrm{i}, \mathrm{t}}$ is the carbon mass concentration of organic pool $\mathrm{i}$ of the applied compost at time $t$ as defined in Table $\mathrm{A} 3$ in SI with $\left(\mathrm{C}_{1}=\mathrm{SDN}_{\mathrm{SLOW}}, \mathrm{C}_{2}=\right.$ $\mathrm{SDN}_{\mathrm{FAST}}, \mathrm{C}_{3}=\mathrm{HCEL}, \mathrm{C}_{4}=\mathrm{CEL}$ and $\left.\mathrm{C}_{5}=\mathrm{LIG}\right)\left[\mathrm{kg} \mathrm{C} / \mathrm{kg}_{\mathrm{cp}} \mathrm{C}\right] ; \mathrm{k}_{\mathrm{Ci}}$ is the hydrolysis constant of pool $\mathrm{Ci}$ in $\left[\mathrm{d}^{-1}\right]$ (see Table A3 in $\mathrm{SI}$ ); $\mathrm{k}_{\mathrm{CS}}$ is the firstorder kinetic constant from $\mathrm{PAH}_{\mathrm{CPWS}}$ to the PAHss compartment $\left[\mathrm{d}^{-1}\right]$;
$\mathrm{f}_{\mathrm{Ci}}$ is the lignin content dependence factor proposed by Corbeels et al. (1999) (see also Iqbal et al., 2014) and $\mathrm{fr}_{\mathrm{i}, \mathrm{t}}$ is a correction factor defined by Eq. (2) as follows:

$\mathrm{fr}_{\mathrm{i}, \mathrm{t}}=\left\{\begin{array}{cc}0 & \text { when } \mathrm{i} \neq 1 \\ \mathrm{w}_{\mathrm{CP}} \cdot\left(1-\mathrm{Y}_{\mathrm{SWCP}}\right) \cdot \mathrm{m}_{\mathrm{cp}} \cdot \mathrm{X}_{\mathrm{cp}, \mathrm{t}} & \text { when } \mathrm{i}=1\end{array}\right.$

For $\mathrm{i}=1$ ( $\left.\mathrm{SDN}_{\text {SLOW }}\right)$, the flux of the dead co-metabolic microorganisms that might be recycled into organic pool $C_{1}$ does not contain any PAH anymore.

The mathematical model uses a set of nonlinear ordinary differential equations that are solved numerically within a MATLAB code. All the model equations are presented in SI Table A1.

\subsection{Experimental data (from Verge-Leviel, 2001)}

The impact of the origin and characteristics of the compost on the PAH dynamics in soil was assessed experimentally by Verge-Leviel (2001). These data are used here to calibrate the PAH model. Three types of incubation containing the PAH have been analysed (Fig. 2a) as follows:

(1) Incubations of composts spiked with PAH to stabilize the PAH in the compost before adding it to the soil and then to create conditions that were closer to reality.

2 Incubations of soil amended with PAH in compost to study the effect of the compost type on the PAH fate in soil. 
(3) Incubation of soil spiked directly with PAH as a control to observe the effect of the stabilization of PAHs in the compost compared to its direct addition to soil.

\subsubsection{Soil and composts}

A silt loam soil was collected from the upper horizon of an agricultural experimental farm located at Palaiseau, near Paris (91, France). Ten sub-samples were collected and mixed to obtain a homogeneous representative composite sample. The soil was sieved at $5 \mathrm{~mm}$ and stored fresh at $4{ }^{\circ} \mathrm{C}$ before use. Its primary characteristics were as follows (in $\mathrm{g} / \mathrm{kg}_{\mathrm{dw}}$ ): clay, 187; silt, 756; sand, 57; and organic C content, 11.9. The soil $\mathrm{pH}$ in water was 5.5 .
The experiments were performed with three composts that were sampled from Veolia composting plants in France during the maturation phase, and they consisted of green waste and sludge compost (GWS), biowaste compost (BioW) and municipal solid waste compost (MSW). The primary characteristics of these composts are detailed in Houot et al. (2012). The composts were sieved at $5 \mathrm{~mm}$.

\subsubsection{Incubation setup}

The following ${ }^{14} \mathrm{C}$-PAHs were used: [9C-ring-14C] phenanthrene (PHE; $1459 \mathrm{MBq} / \mathrm{mmol}$; >98\% purity), [3C-ring-14C] fluoranthene (FLT; $1665 \mathrm{MBq} / \mathrm{mmol}$; 98\% purity) and [7C-ring-14C] benzo(a)pyrene (BAP; $984 \mathrm{MBq} / \mathrm{mmol}$; >98\% purity). ${ }^{14} \mathrm{C}$-labelled and non-labelled
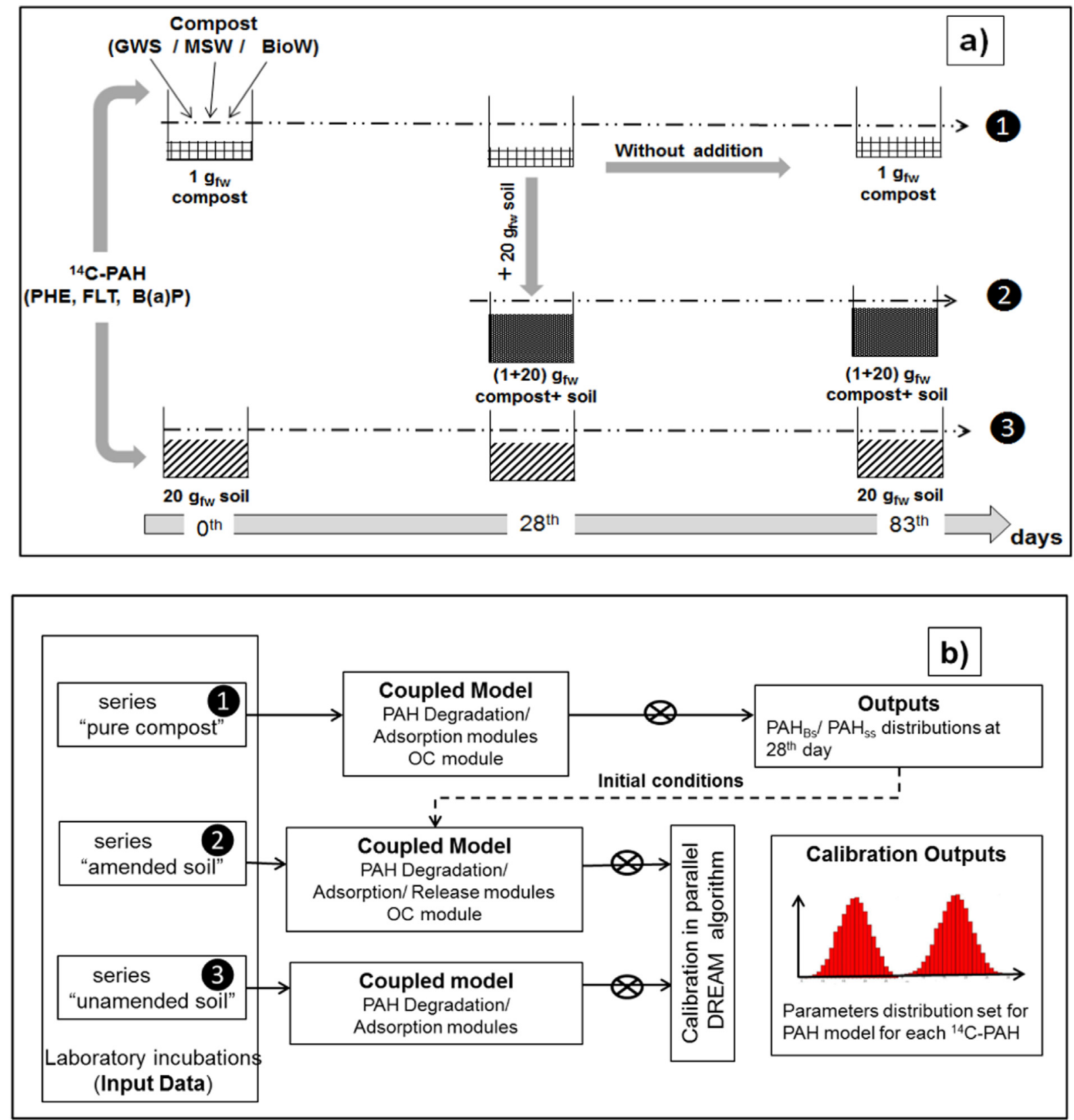

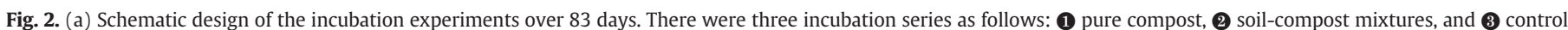

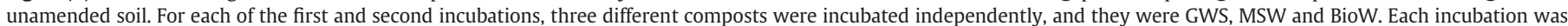

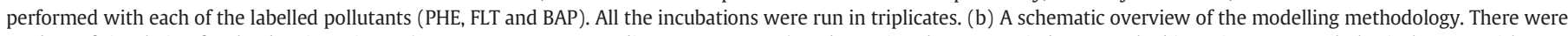

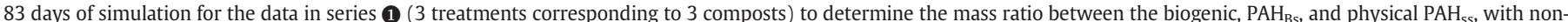

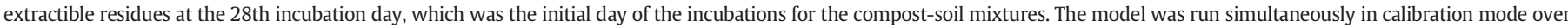

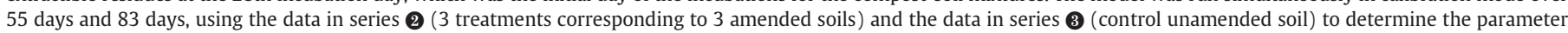
distribution set of the PAH model for each $\mathrm{PAH}$. 
PAHs were purchased from Sigma (St. Quentin Fallavier, France). Solutions of the labelled pollutants were first prepared in methanol. The radioactivity levels of the prepared solutions were 29.899, 34.481 and 47.709 MBq/L for PHE, FLT and BAP, respectively. The final concentrations were adjusted with non-labelled PAH at $13 \mathrm{mg} / \mathrm{L}$ for each PAH.

The incubation experiments were performed as follows. One hundred microliters of each ${ }^{14} \mathrm{C}$-PAH solution was added to $1 \mathrm{~g}_{\mathrm{fw}}$ of compost in $100 \mathrm{~mL}$ glass jars. The closed jars were then pre-incubated for 28 days at $28{ }^{\circ} \mathrm{C}$. On the 28 th day, $20 \mathrm{~g}_{\mathrm{fw}}$ soil (water content equivalent to $\mathrm{pF}=$ 2.5) was added and the incubation of the soil-compost mixtures (20:1) was performed for 55 additional days at $28{ }^{\circ} \mathrm{C}$ (series 2 in Fig. 2a). Control incubations containing only ${ }^{14} \mathrm{C}-\mathrm{PAH}$ solution with compost or soil were run simultaneously under the same conditions for 83 days (series 1 and 3 in Fig. 2a). All the experiments were run in triplicates.

\subsubsection{Analysis (see SI 2 for details)}

The $\mathrm{C}-\mathrm{CO}_{2}$ org and ${ }^{14} \mathrm{C}-\mathrm{CO}_{2}$ from the mineralization of the total organic carbon and the ${ }^{14} \mathrm{C}-\mathrm{PAH}$, respectively, were periodically measured on days $3,7,10,14,21,28,31,36,41,47,54,61,67,74$ and 83 . The distributions of ${ }^{14} \mathrm{C}$-PAH among the metabolites, parent extractible pollutant and the non-extractible and mineralized fractions were assessed on days 28 and 83 for each incubation.

\subsubsection{Experimental data handling}

Assuming the mineralized fraction was precisely measured compared to the measured extractable and non-extractable fractions, the yields of the three fractions were adjusted to $100 \%$ recovery by applying a weight distribution error to the metabolites and the parent extractible and non-extractible fractions at each of the two extraction times. To assess the suitability of the raw data for the purpose of modelling, a twofactor analysis of variance (ANOVA) with replication was performed to verify whether a significant difference was present between the four treatments (i.e., the 3 different composts + soil, in addition to the control soil without amendment) across both days and the type of analysed fraction on the dissipation of labelled ${ }^{14} \mathrm{C}$-PAH through the soil-compost mixture system.

The model parameters were fitted to the experimental fractions. The measured mineralized fraction was assigned to the simulated $\mathrm{PAH}_{\mathrm{CO} 2}$ and the extractible metabolite fraction corresponded to the simulated $\mathrm{PAH}_{\mathrm{MET}}$, whereas the non-extractible fraction (NER) corresponded to the two model compartments that were pooled together, namely the biogenic residue $\mathrm{PAH}_{\mathrm{Bs}}$ and the physical residue $\mathrm{PAH}_{\mathrm{ss}}$. The extractible fraction of the parent compound in the soil-compost mixtures system corresponded to the available soluble compartment $\mathrm{PAH}_{\mathrm{AV}}$ and the two adsorbed compartments $\mathrm{PAH}_{W S}$ and $\mathrm{PAH}_{C P W S}$ (see SI 3). The initial soil microbial biomasses, $\mathrm{X}_{\text {soil }}, \mathrm{Xcp}$ and Bspe, were taken as explained in SI 1.

\subsection{Modelling methodology}

Four groups of runs were performed sequentially as summarized in Table 1 and Fig. 2b. While the two first runs of models 1 and 2 were conducted with the $\mathrm{OC}$ model alone, the two other runs 3 and 4 were implemented with a PAH model coupled to an OC model. Runs 1 and 3 were performed to simulate the compost incubations to calculate the amount and distribution of non-extractable PAHs between biogenic and strongly sorbed fractions at 28 days $\left(\mathrm{PAH}_{\mathrm{Bs}}\right.$ and $\mathrm{PAH}_{\mathrm{Ss}}$, respectively) that were not available from the experimental data. Runs 2 and 4 were used to estimate a set of parameters that could simulate all the treatments in the soil-compost mixtures for each PAH. In run 3 (of soil amended with composts), the initial data for the PAH compartments were obtained from the experimental data obtained on the 28th day of the compost experiments.

During run 4, the DREAM algorithm (Vrugt, 2016) was inserted into the code of the coupled model and was used to estimate the probability density functions of the PAH model parameters in the soil (see more
Table 1

The calibration procedures.

\begin{tabular}{|c|c|c|}
\hline \# Run & Data set & Object6ives \\
\hline $\begin{array}{l}\mathrm{N}^{\circ} 1 \\
\text { OC Model } \\
\text { In compost } \\
3 \text { composts }\end{array}$ & $\begin{array}{l}\mathrm{CO}_{2} \text { mineralized } \\
\text { Fig. 2, series } 1\end{array}$ & $\begin{array}{l}\text { Calibration of } O C \text { model parameters to be used } \\
\text { by run } \mathrm{N}^{\circ} 3 \\
\text { Table } \mathrm{A} 3 \text { and Fig. } 3(\mathrm{a}, \mathrm{b})\end{array}$ \\
\hline $\begin{array}{l}\mathrm{N}^{\circ} 2 \\
\text { OC Model } \\
\text { In } \\
\text { soil-compost } \\
\text { mixture } \\
3 \text { composts }\end{array}$ & $\begin{array}{l}\mathrm{CO}_{2} \text { mineralized } \\
\text { from compost } \\
\text { Fig. 2, series } 2\end{array}$ & $\begin{array}{l}\text { Calibration of the } \mathrm{OC} \text { model parameters to be } \\
\text { used by run } \mathrm{N}^{\circ} 4 \\
\text { Table A3 and Fig. } 3 \text { (c, d) }\end{array}$ \\
\hline $\begin{array}{l}\mathrm{N}^{\circ} 3 \\
\text { Coupling } \\
\text { model OC } \times \\
\mathrm{PAH} \\
\text { In compost } \\
3 \text { composts } \times \\
3 \mathrm{PAH}\end{array}$ & $\begin{array}{l}{ }^{14} \mathrm{C}-\mathrm{CO}_{2} \\
\text { mineralized } \\
{ }^{14} \mathrm{C}-\mathrm{PAH} \\
\text { fractions } \\
\text { Fig. 2, series } 1\end{array}$ & $\begin{array}{l}\text { Determining the ratio between biogenic NER } \\
\mathrm{PAH}_{\mathrm{BS}} \text { and strongly sorbed } \mathrm{PAH}_{\mathrm{SS}} \text { at the } 28 \text { th } \\
\text { day of compost incubations/initial time of } \\
\text { soil-compost incubations run } \mathrm{N}^{\circ} 4 \\
\text { Table A4 and Fig. } 4\end{array}$ \\
\hline $\begin{array}{l}\mathrm{N}^{\circ} 4 \\
\text { Coupling } \\
\text { model OC } \times \\
\text { PAH } \\
\text { In } \\
\text { soil-compost } \\
\text { mixture } \\
\text { In soil control } \\
3 \text { composts } \times \\
3 \text { PAH } \\
1 \text { sol } \times 3 \text { PAH }\end{array}$ & $\begin{array}{l}{ }^{14} \mathrm{C}-\mathrm{CO}_{2} \\
\text { mineralized } \\
{ }^{14} \mathrm{C}-\mathrm{PAH} \\
\text { fractions } \\
\text { Fig. 2, series } 2 \\
{ }^{14} \mathrm{C}-\mathrm{PAH} \\
\text { fractions } \\
\text { Fig. 2, series } 3\end{array}$ & $\begin{array}{l}\text { Get } 1 \text { set of parameters to simulate each PAH } \\
\text { for the } 3 \text { compost-soil mixtures and the soil } \\
\text { control } \\
\text { Table } 2 \text { and Figs. 6, A1, A2, A3 }\end{array}$ \\
\hline
\end{tabular}

details in Brimo et al., 2016)). The parameter ranges required by DREAM as prior parameter distributions were chosen on the basis of the literature survey and further adjusted using a stepwise trial and error strategy. Each run included a maximum total of 5000 model simulations, and only the best $50 \%$ of the simulations were chosen (Brimo et al., 2016)) and used to build the histograms of the probability density functions in the model parameter values. A Nash Sutcliffe index (Nash and Sutcliffe, 1970) was calculated to perform a quantitative evaluation of the model accuracy.

\section{Results and discussion}

\subsection{Calibration of the OC model for the control compost and amended soil}

The OC model required a parameter calibration prior to use. We chose to optimize the hydrolysis rates of the cellulose (CEL) and hemicellulose (HCEL) pools so that $\mathrm{k}_{\mathrm{CEL}}$ is equal to $\mathrm{k}_{\mathrm{HCEL}}$ because Iqbal et al. (2014) found that the CEL and HCEL organic pools have similar decomposition rates. The OC calibration yielded an estimated value of $0.03 \mathrm{~d}^{-1}$ for both the $\mathrm{k}_{\mathrm{CEL}}$ and $\mathrm{k}_{\mathrm{HCEL}}$ parameters in the model of pure composts and a very similar value of $0.02 \mathrm{~d}^{-1}$ in the amended soil. The updated values of $\mathrm{k}_{\mathrm{CEL}}$ and $\mathrm{k}_{\mathrm{HCEL}}$ obtained through this study were very close to the $0.028 \mathrm{~d}^{-1}$ reported by Iqbal et al. (2014) for crop residue decomposition in soil.

Zhang et al. (2012) reported that the soluble organic pool would have very different characteristics in the fast pool $\left(\mathrm{SDN}_{\text {fast }}\right)$ and the slow pool $\left(\mathrm{SDN}_{\text {slow }}\right)$ depending on the origin of the compost. Consequently, during the compost incubation, we also re-adjusted the parameter $\mathrm{k}_{\text {fast }}$ (hydrolysis rate of the fast soluble pool) and found an estimated value of $0.212 \mathrm{~d}^{-1}$ for $\mathrm{k}_{\mathrm{fast}}$. In the amended soil, we also fit both the parameters linked to the microbial biomass, namely, the mortality rate and the proportion of recycling dead microbial biomass $\left(\mathrm{m}_{\mathrm{cp}}\right.$, and $w_{c p}$, respectively), because Zhang et al. (2012) found that the organic mineralized fraction $\left(\mathrm{CO}_{2}\right.$ org $)$ was very sensitive to the parameters linked to the microbial biomass. The calibration in amended soil yielded an estimated value of $0.085 \mathrm{~d}^{-1}$ for $\mathrm{m}_{\mathrm{cp}}$ and two different estimated 
values for $\mathrm{w}_{\mathrm{cp}}$. Their values were $0.1 \%$ in GWS and BioW, which were also the same as that obtained by Geng et al. (2015) for a GWS treatment, whereas the estimated value with MSW was 99.9\%. These results indicated that the microbial biomass was recycled in the immature compost MSW treatments while the more stable composts such as GWS and BioW were made directly into soil-humified organic matter. The updated sets of parameters for the OC model are summarized in Table A3 in SI. A single set of parameters was found to simulate the dynamics of $\mathrm{OC}$ adequately in all the composts for each type of incubation in the pure composts and amended soils.

The evolution of organic carbon mineralization into $\mathrm{CO}_{2}, \mathrm{CO}_{2}$ org, and microbial biomass are displayed in Fig. 3. According to Fig. 3 (a and c), there is very good consistency between the simulated and experimental data obtained for $\mathrm{CO}_{2}$ org as confirmed by the high Nash Sutcliffe efficiency indexes of $0.97,0.84$, and 0.89 for the MSW, BioW, and GWS treatments, respectively, in the pure composts, and of $0.99,0.98$, and 0.90 for MSW, BioW, and GWS, respectively, in the amended soils. During the initial step of the incubations of the control composts (Fig. 3a and b), a rapid mineralization and a significant increase in the microbial biomass are observed. At the end of the simulation period, the mineralized $\mathrm{CO}_{2 \text { org }}$ levels in the treatment driven by MSW are 1.7 to 3.8 times higher than that observed in the BioW and GWS treatments, respectively. The maximum predicted peak for biomass growth is higher in the BioW treatment than in the MSW and GWS treatments. However, after reaching the maximum peak, the microbial biomass in the MSW treatment remains much higher than it was in the BioW and GWS (Fig. $3 \mathrm{~b})$. Following the compost applications to the soil (Fig. 3c and d), the dynamics of OC decomposition for the different treatments in amended soil followed the same order as those that were previously found in the pure compost incubations but with much higher mineralization and microbial growth in the MSW in comparison to the other treatments. This result showed that the MSW compost was not mature when it was sampled from the composting plants or after 28 days of incubation by itself, compared to the other one. These varying behaviours for the different composts during the incubations can be attributed to the origin and the degree of maturity of the applied compost as reported by Chalhoub et al. (2013), Francou et al. (2008) and Zhang et al. (2012).

\subsection{Simulation of PAH fractions in compost}

As previously mentioned, we first predicted the dynamics of the ${ }^{14} \mathrm{C}$ PAH during the 83 days of compost incubations, but we identified the initial conditions of the compost when it was added to the soil on the 28th day. All the simulations were performed using the PAH model coupled to the OC model. The model was calibrated for each compost and each PAH. Table A6 in the SI gives the Nash-Sutcliffe efficiencies for the extractible $\mathrm{PAH}$, the metabolites, the total non-extractible and the mineralized fractions for each of the three ${ }^{14} \mathrm{C}$-PAHs. The performance of the model in reproducing the experimental measurements was good, as confirmed by the Nash Sutcliff efficiency index that was generally $>0.60$, except for the metabolite fractions measured in the MSW treatment that registered negative Nash Sutcliff index values. The discrepancy between the simulations and experiments in the MSW treatment was primarily due to the model overestimation of the data at the end of the incubation.

The simulated results for the non-extractible residues $\left(\mathrm{PAH}_{\mathrm{SS}}\right.$ $\left.+\mathrm{PAH}_{\mathrm{BS}}\right)$ and the mineralized fraction $\left(\mathrm{PAH}_{\mathrm{CO} 2}\right)$ for each ${ }^{14} \mathrm{C}-\mathrm{PAH}$ over all the treatments are presented in Fig. 4 using the estimated parameters of Fig. A4. The amount of mineralized $\mathrm{CO}_{2}$ increased in the following order: BAP, FLT and PHE, because of the higher microbial degradation due to their lower number of benzene rings. We found that the highest mineralization intensity was obtained in the treatments containing BioW and GWS composts for all the PAHs. Lower mineralization was observed in the incubations with MSW compost. This finding suggests that the potential amounts of microorganisms that were degrading the organic pollutants should have been smaller in the treatment with MSW compost in comparison to the GWS and BioW, as already mentioned in Houot et al. (2012). These observations contrast with the results for the organic decomposition of the three composts, where the mineralization was significantly higher for the MSW than for the GWS and BioW composts (Fig. 3). To fit the data, the model

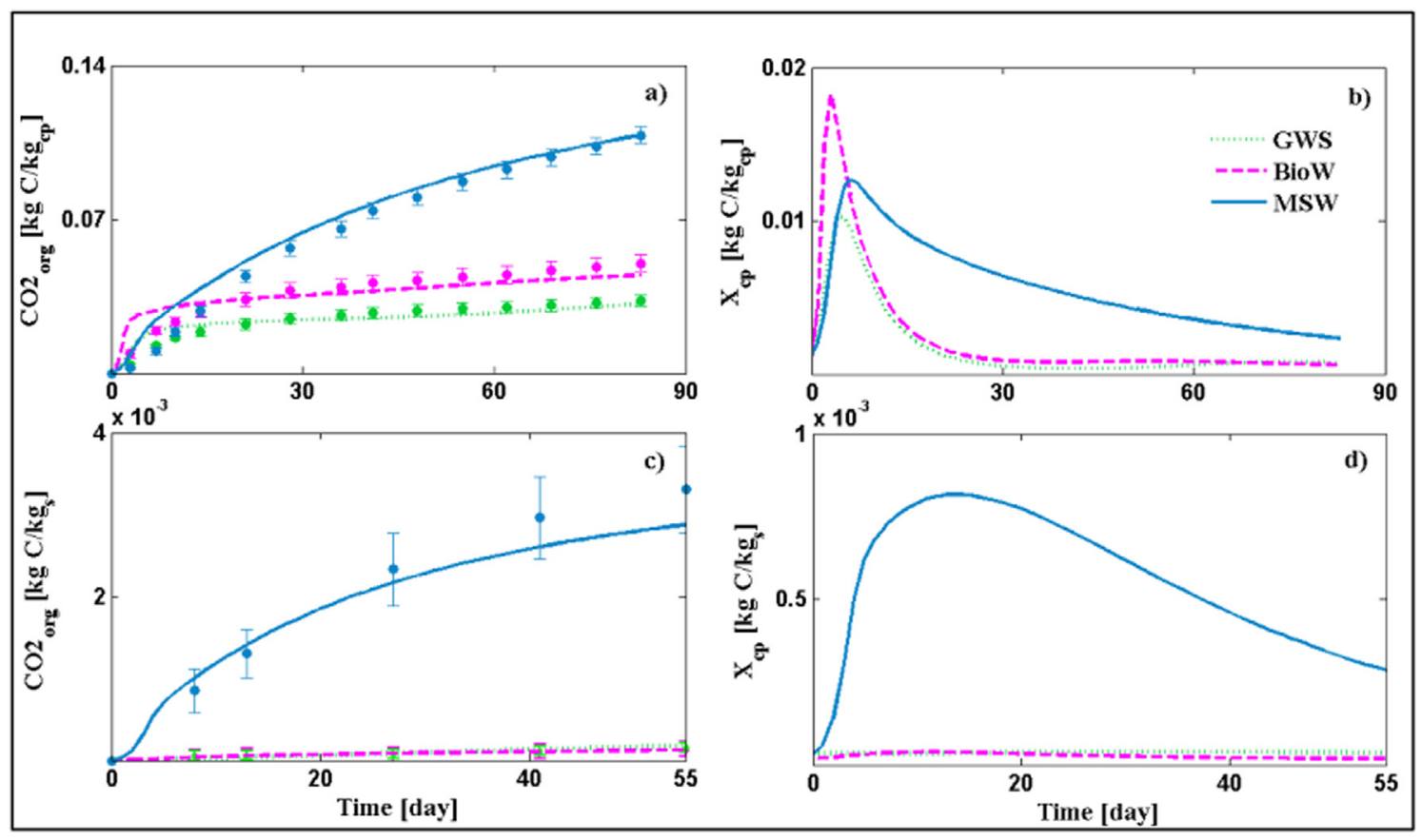

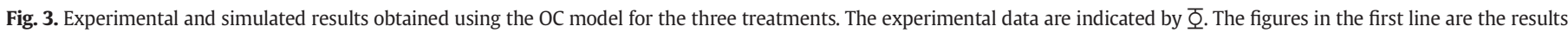

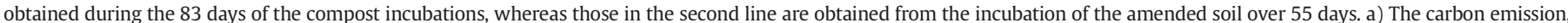

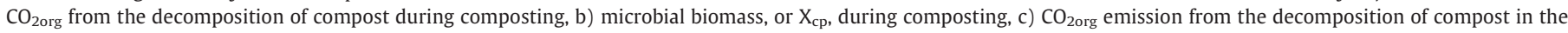

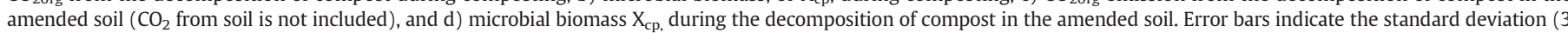
replicates). 


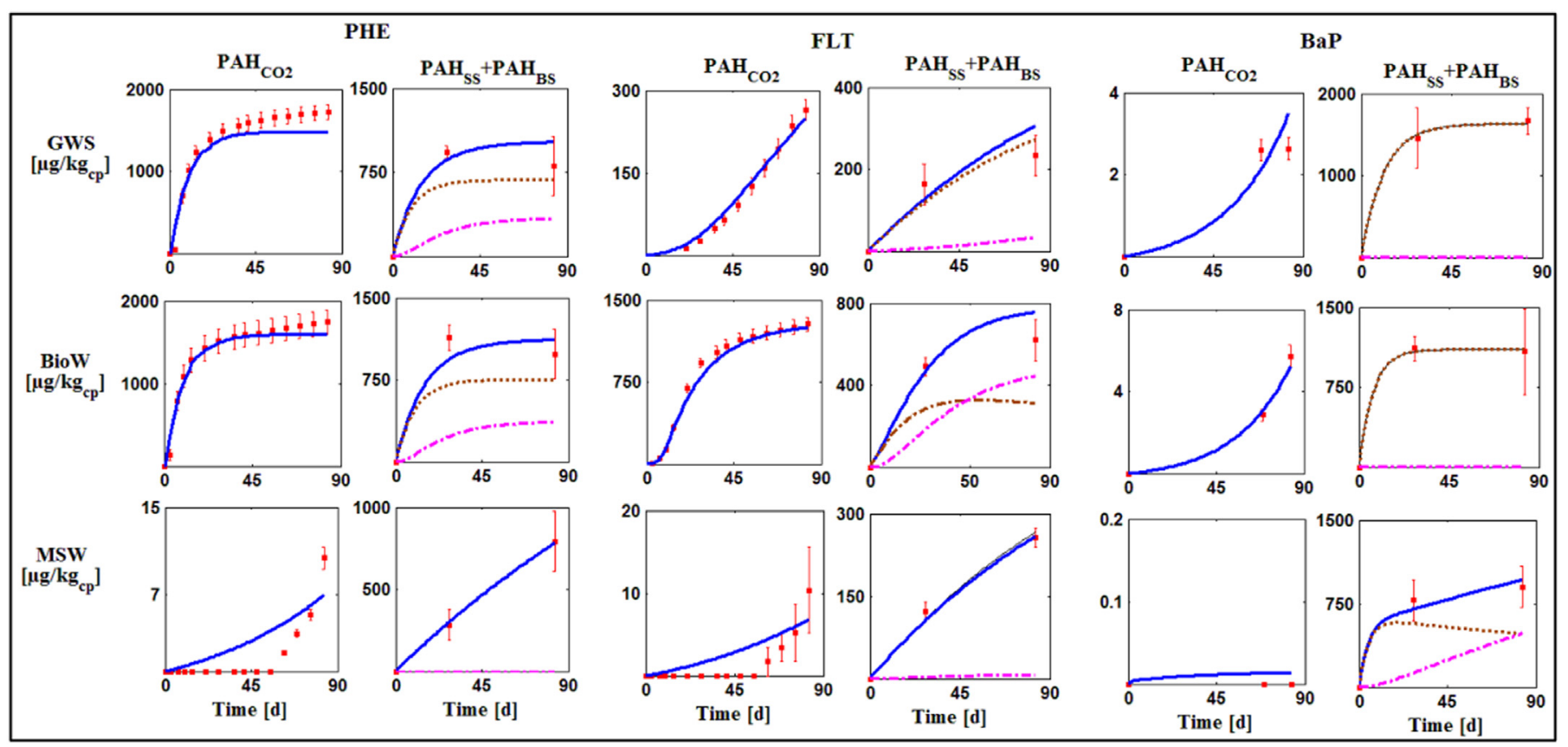

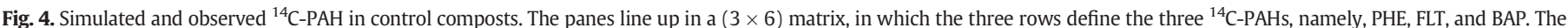

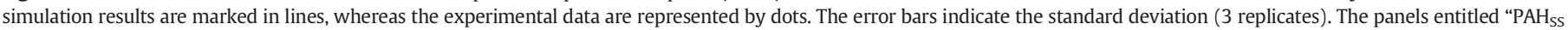

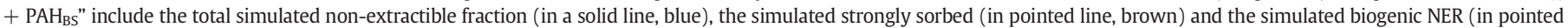

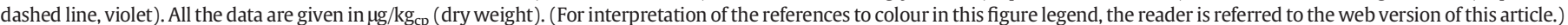

therefore simulated that the biodegradation of the labelled pollutants into ${ }^{14} \mathrm{C}_{-} \mathrm{CO}_{2}$ and $\mathrm{PAH}_{\mathrm{CO} 2}$ occurred through the pathway that was driven by the specific biomass and not only by the co-metabolism pathway (Fig. 5). This assumption is supported by Cerniglia (1997), who reported that composts rich in lignin, including ligninolytic fungi, can be efficient at the bioremediation of PAH in contaminated wastes. Houot et al. (2012) found higher PAH mineralization in GWS and BioW than in
MSW, and they concluded that the maturation microflora was more efficient than the thermophilic microflora at mineralizing organic pollutants. The PAH mineralization was well simulated in the treatments with BioW and GWS composts when considering both biodegradation pathways. By contrast, regarding the treatment with MSW compost, the model predicted that the mineralized fraction was produced only through the specific biomasses pathway and not from the co-
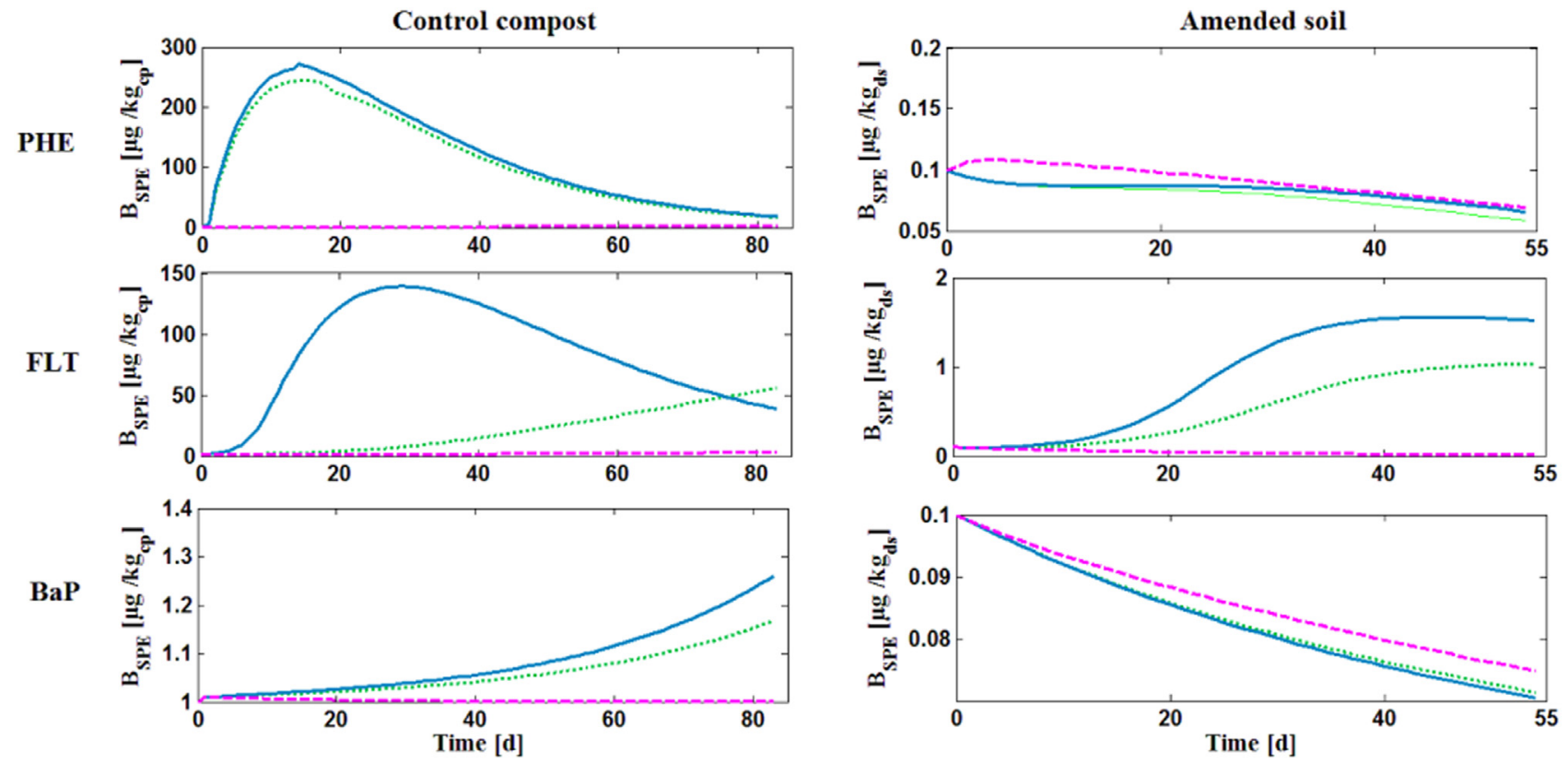

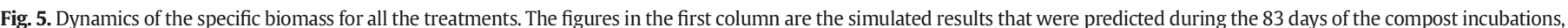

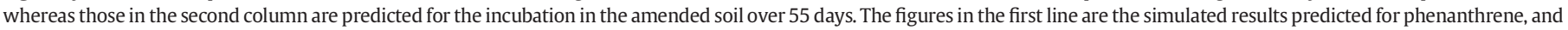

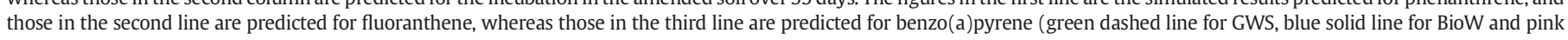
dashed line for MSW). 
metabolic one. The model simulated a very low specific biomass (Fig. 5). This result was corroborated by the observed initial lag-phases in the mineralized fraction with this treatment.

The proportion of biogenic non-extractible residues, or the $\mathrm{PAH}_{\mathrm{BS}}$ (referring to the total non-extractible residues fractions, $\mathrm{PAH}_{\mathrm{NER}}$ ) after the 28th day of composting (days during which the composts were amended into the soil) are given in Fig. 4 and Table A5. A very low percentage of biogenic non-extractible residues was predicted for the FLT and PHE in the MSW compost. The model estimated much higher $\mathrm{PAH}_{\mathrm{BS}}$ for BAP at approximately $18.7 \%$. We observed that the higher the mineralization rates of ${ }^{14} \mathrm{C}$-PAH were, the higher the model estimation of the biogenic contribution to the total non-extractible residues (Fig. 4 and Table A5). These findings are consistent with the results reported in the literature about the biogenic bounded residue formation. There are numerous references reporting that the microbial activity has a direct and significant effect on the formation of non-extractible residues for persistent organic pollutants (Barriuso et al., 2008; Gevao et al., 2005; Kästner et al., 1999; Nowak et al., 2013). However, the biogenic rates of formation during the incubations remain unknown because no chemical analyses were performed and very few studies can be found in the literature about the quantification or the modelling of biogenic residue formation during compost incubations or in compost-amended soil. We found that the biogenic residues were systematically lower than the strongly sorbed residues (see Fig. 4). Richnow et al. (2000) found that the contribution of the biogenic fraction to the total non-extractible residues for PHE was at least $11 \%$ after 50 days of incubation in a batch bioreactor. Kästner et al. (2014) simulated the dynamics of anthracene (PAH with 3 cycles) in nonamended soil and predicted that $50 \%$ of the non-extractible residues were biogenic after 50 days of simulations.

\subsection{Simulation of PAH fractions in amended soils}

The PAH model coupled with the DREAM algorithm was run to determine the best set of model parameter values for soil-compost incubations for each PAH. The initial conditions were obtained from the ${ }^{14} \mathrm{C}$ $\mathrm{PAH}$ distribution at the 28th day of the pure compost incubations. The best set of model parameters was the one that simulated the observed data as accurately as possible, as recorded for the pollutant in the amended soil with the three different composts and the unamended soil.

\subsubsection{Estimated parameters}

A single set of parameters for all the compost types was found to simulate the dynamics of PHE and BAP independently (Table 2). However, this single parameter set could not be determined for the FLT where different values were found for the Kcs parameter (the rate of strongly sorbed compartment formation from compost PAH) and the $\mu$ max (the maximum growth rate of a specific biomass).

The 95\% confidence intervals listed in Table 2 for each estimated parameter were obtained from DREAM by using the histograms of the probability density functions (PDF) in the parameter value range (Fig. A4). The results show that some parameters were very well-defined since their histograms of values display Gaussian distributions with 95\% confidence intervals, occupying small ranges inside the uniform prior distributions. This was also the case for the parameters $\mathrm{k}_{\mathrm{SW}}, \mathrm{k}_{\mathrm{WS}}$, $\mathrm{k}_{\mathrm{CS}}$ and $\mathrm{k}_{\mathrm{MB}}$ for PHE. However, some other parameters had more uniform PDF and/or they concentrated most of their probability mass at their lower or higher limits. These parameters are linked to the biodegradation pathway driven by specific biomasses $\left(\mu \mathrm{s}_{\max }, \mathrm{k}_{\mathrm{M}}, \mathrm{y}_{\mathrm{spe}}\right.$, and $\left.\mathrm{ks}_{\text {spe }}\right)$. This finding was probably due to the lack of data for measuring the specific degradation. Low correlations were found between the parameters except between the sorption parameters $\mathrm{k}_{\mathrm{sw}}$ and $\mathrm{k}_{\mathrm{WS}}$, with a correlation coefficient of 0.75 . A comparison of the parameter values obtained in this current study with their values published in the literature was difficult because of the differences between the models. The fitted parameter values of the co-metabolism biodegradation pathway $\mathrm{k}_{\mathrm{deg}}$ were found to be in the following order: PHE $>$ FLT $>$ BAP, which was correlated to the bioavailability of the pollutant itself as linked to its chemical hydrophobicity. The fitted value for the $\mu s_{\max }$ of FLT in the GWS of $0.54 \mathrm{~d}^{-1}$ was close to the value obtained by Geng et al. (2015) for the same PAH in the same compost. The optimized values of $\mathrm{y}_{\text {spe }}$ for PHE and FLT (0.251 and 0.274 [ - ] respectively) were found to be close to that proposed by Weissenfels et al. (1990) (0.24 and $0.23[-]$ for PHE and FLT respectively).

\subsubsection{Performance of the model}

Two Nash Sutcliff efficiency index (NS) values were calculated for each ${ }^{14} \mathrm{C}$-PAH and each treatment (Table 3). While the first one, $\mathrm{NS}_{\text {global, }}$, was used to evaluate the goodness of fit for all the model variables together, the second one, the $\mathrm{NS}_{\mathrm{CO}}$, accounted for the goodness of fit for the mineralized variable $\mathrm{PAH}_{\mathrm{CO} 2}$ alone. In general, the overall performance demonstrated the good ability of the model to describe the observed PAH transformation in soil, as confirmed by the relatively high

Table 2

Optimal values and confidence intervals (CI) of PAH model parameters obtained with DREAM for the three ${ }^{14} \mathrm{C}$-PAH in amended soils.

\begin{tabular}{|c|c|c|c|c|c|c|c|}
\hline \multirow[t]{2}{*}{ Par } & \multirow[t]{2}{*}{ Unit } & \multicolumn{2}{|c|}{ Phenanthrene } & \multicolumn{2}{|c|}{ Fluoranthene } & \multicolumn{2}{|c|}{ Benzo(a)pyrene } \\
\hline & & Optimum & $95 \% \mathrm{CI}$ & Optimum & $95 \% \mathrm{CI}$ & Optimum & $95 \% \mathrm{CI}$ \\
\hline $\mathrm{k}_{\mathrm{AW}}$ & $\mathrm{d}^{-1}$ & 1.770 & {$[0.484,3.865]$} & 26.428 & {$[1.44,28.06]$} & 24.810 & {$[15.04,28.15]$} \\
\hline $\mathrm{k}_{\mathrm{WA}}$ & $d^{-1}$ & 0.230 & {$[0.079,0.238]$} & 0.932 & {$[0.0124,0.94]$} & 0.218 & {$[0.075,0.354]$} \\
\hline $\mathrm{k}_{\mathrm{WS}}$ & $d^{-1}$ & 0.065 & {$[0.030,0.10]$} & 0.021 & {$[0.021,0.114]$} & 0.029 & {$[0.0274,0.036]$} \\
\hline $\mathrm{k}_{\mathrm{SW}}$ & $\mathrm{d}^{-1}$ & 0.032 & {$[0.027,0.045]$} & 0.042 & {$[0.037,0.199]$} & 0.007 & {$[0.005,0.012]$} \\
\hline $\mathrm{k}_{\mathrm{MB}}$ & $d^{-1}$ & 0.037 & {$[0.037,0.149]$} & 0.065 & {$[0.017,0.096]$} & 0.138 & {$[0.079,0.184]$} \\
\hline $\mathrm{k}_{\mathrm{CS}}$ & $\mathrm{d}^{-1}$ & 0.238 & {$[0.10,0.570]$} & $\begin{array}{l}0.002^{\mathrm{a}} \\
0.016^{\mathrm{b}} \\
0.06^{\mathrm{c}}\end{array}$ & {$\left[5 \times 10^{-4}, 2 \times 10^{-2}\right]$} & $6 \times 10^{-4}$ & {$\left[1 \times 10^{-4}, 1 \times 10^{-3}\right]$} \\
\hline $\mathrm{k}_{\mathrm{deg}}$ & $\left(\mathrm{mg} \mathrm{C} / \mathrm{kg}_{\mathrm{dw}} \cdot \mathrm{d}\right)$ & $2.7 \times 10^{-3}$ & {$\left[2 \times 10^{-3}, 2 \times 10^{-2}\right]$} & $2.2 \times 10^{-4}$ & {$\left[1 \times 10^{-2}, 2 \times 10^{-3}\right]$} & $1.7 \times 10^{-4}$ & {$\left[6 \times 10^{-5}, 3 \times 10^{-4}\right]$} \\
\hline$\beta$ & - & 0.478 & {$[0.385,0.498]$} & 0.59 & {$[0.445,0.597]$} & 0.59 & {$[0.356,0.597]$} \\
\hline$\mu s_{\max }$ & $\mathrm{d}^{-1}$ & 2.606 & {$[1.786,11.29]$} & $\begin{array}{l}8.423^{\mathrm{d}} \\
0.54^{\mathrm{e}}\end{array}$ & {$[0.394,11.237]$} & 0.908 & {$[0.227,1.685]$} \\
\hline $\mathrm{ks}_{\text {spe }}$ & $\mu \mathrm{g}{ }^{14} \mathrm{C} / \mathrm{kg} \mathrm{dw}_{\mathrm{w}}$ & 36.627 & {$[25.52,71.26]$} & 12.133 & {$[3.82,73.3]$} & 46.256 & {$[16.65,58.56]$} \\
\hline$Y_{\text {spe }}$ & - & 0.251 & {$[0.13,0.275]$} & 0.274 & {$[0.112,0.289]$} & 0.166 & {$[0.124,0.246]$} \\
\hline $\mathrm{k}_{\mathrm{M}}$ & $\mathrm{d}^{-1}$ & 0.035 & {$[0.005,0.088]$} & 0.043 & {$[0.0044,0.0897]$} & 0.018 & {$[0.015,0.087]$} \\
\hline
\end{tabular}

a,b,c Optimum values for $\mathrm{k}_{\mathrm{CS}}$ for the amended soil with GWS, BioW, MSW respectively.

${ }^{d}$ Optimum value for $\mu s_{\max }$ for the amended soil with GWS and BioW.

e Optimum value for $\mu s_{\max }$ for the amended soil with MSW. 
Table 3

Nash Sutcliff index values as calculated in soils for $\mathrm{CO}_{2}$ alone and for all the compartments together.

\begin{tabular}{|c|c|c|c|c|c|c|}
\hline \multirow[t]{2}{*}{ Treatment } & \multicolumn{2}{|c|}{ Phenanthrene } & \multicolumn{2}{|c|}{ Fluoranthene } & \multicolumn{2}{|c|}{ Benzo(a)pyrene } \\
\hline & $\mathrm{NS}_{\text {global }}$ & $\mathrm{NS}_{\mathrm{CO} 2}$ & $\mathrm{NS}_{\text {global }}$ & $\mathrm{NS}_{\mathrm{CO} 2}$ & $\mathrm{NS}_{\text {global }}$ & $\mathrm{NS}_{\mathrm{CO} 2}$ \\
\hline GWS & 0.98 & 0.78 & 0.99 & 0.99 & 0.9 & 0.84 \\
\hline BioW & 0.97 & 0.60 & 0.75 & 0.01 & 0.99 & 0.99 \\
\hline MSW & 0.95 & 0.92 & 0.98 & 0.88 & 0.99 & 0.98 \\
\hline Unamended soil & 0.98 & 0.95 & 0.99 & 0.96 & 0.99 & 0.28 \\
\hline
\end{tabular}

$\mathrm{NS}_{\text {global }}$ values that were above 0.75 for most of the simulation situations. The performance of the model in simulating the mineralized fractions was generally good and the $\mathrm{NS}_{\mathrm{CO} 2}$ values were close to 1 for many simulations. Still, for some situations, a poor performance was achieved, as with the BAP for unamended soil $\left(\mathrm{NS}_{\mathrm{CO} 2}=0.28\right)$ or with the FLT for biowaste $\left(\mathrm{NS}_{\mathrm{CO} 2}=0.01\right)$. In fact, the simulated curves were obtained using a unique parameter set that corresponded to the best compromise over the entire treatments, thus resulting in high discrepancies for some cases.

\subsubsection{Comparison between the experimental and simulated results}

The observed and simulated dynamics of the three PAHs in the soils that were amended with the three composts and in the unamended soil are presented in Figs. 6, A1, A2, and A3. These results could be explained by i) the physiochemical properties of the $\mathrm{PAH}$, ii) the initial amount and distribution of PAHs in compost fractions and iii) the degradability of the composts.

As already observed in the compost (section 3.2), the amount of ${ }^{14} \mathrm{CO}_{2}$ that was mineralized for the BAP and FLT was much lower than the ${ }^{14} \mathrm{CO}_{2}$ mineralized for the PHE (Fig. 6) because their higher number of benzene rings compared to PHE was more difficult to degrade by microorganisms. For the PHE, a decrease in the mineralization was observed in the following order: unamended soil $>$ MSW $>$ BioW $=$ GWS. Similar orders were obtained for BAP, but for FLT, a higher mineralization was obtained with the BioW treatment in comparison to the three others but with no significant differences. For the BAP and PHE, the total amount of PAH brought by the MSW was higher than what was brought with GWS and BioW because of the low PAH mineralization observed in the MSW during the composting process. The higher microbial growth stimulated by the high decomposition of the MSW compared to the BioW/GWS (Fig. 3) may enhance the degradation by co-metabolism in this compost. PHE was localized in adsorbed fractions for unamended soil and MSW (Fig. 6, A1, A2, A3) and thus was available for microorganisms, while it was initially present primarily in NER fractions of BioW and GWS and thus was less available for microorganisms. For these two PAHs, the mineralization in unamended soils was higher than it was in amended soils because the bioavailability of $\mathrm{PAH}_{\mathrm{AV}}$ in the soil alone was much higher than that of the $\mathrm{PAH}_{\mathrm{AV}}$ coming from the release of PAHs from the compost $\mathrm{PAH}_{\mathrm{CPWS}}$ in amended soil. For the FLT, we observed a higher mineralization for the BioW compared to the other treatments, although a lower amount was added with BioW. The BioW compost was also the treatment that mineralized the FLT more during composting, as shown in section 3.2. The degradation by a specific biomass from BioW (Fig. 5) may explain this higher mineralization in this treatment, as explained below.

Figs. 3 and 5 and Figs. A1, A2, and A3 (in the last columns) show the simulated total and specific biomass evolution during the incubation. For PHE and BAP, the simulated results highlighted that the biodegradation of PAH was primarily driven by co-metabolic microbial biomasses in amended soils, because the specific biomass decreased during the incubations. In unamended soil for PHE, the growth of the specific microbial biomass indicated that a specific biomass was also involved in the degradation of the PAH. For FLT, the model predicted a growth of specific biomass for GWS and BIOW, indicating that a part of the mineralization fraction was formed through the specific biodegradation pathway (Fig. 5). For the FLT, we could not use the same parameters for all the treatments and we had to estimate the growth rate of specific microorganisms $\left(\mu S_{\max }\right)$ for each treatment, as shown in Table 2. In fact, Geng et al. (2015) also found the degradation of FLT by a specific biomass pathway, and Brimo et al. (2016) found that the model output is very sensitive to this parameter. We found a higher growth rate of specific microorganisms for BioW and GWS compared to MSW. Houot et al. (2012) showed that specific microflora were higher in mature composts

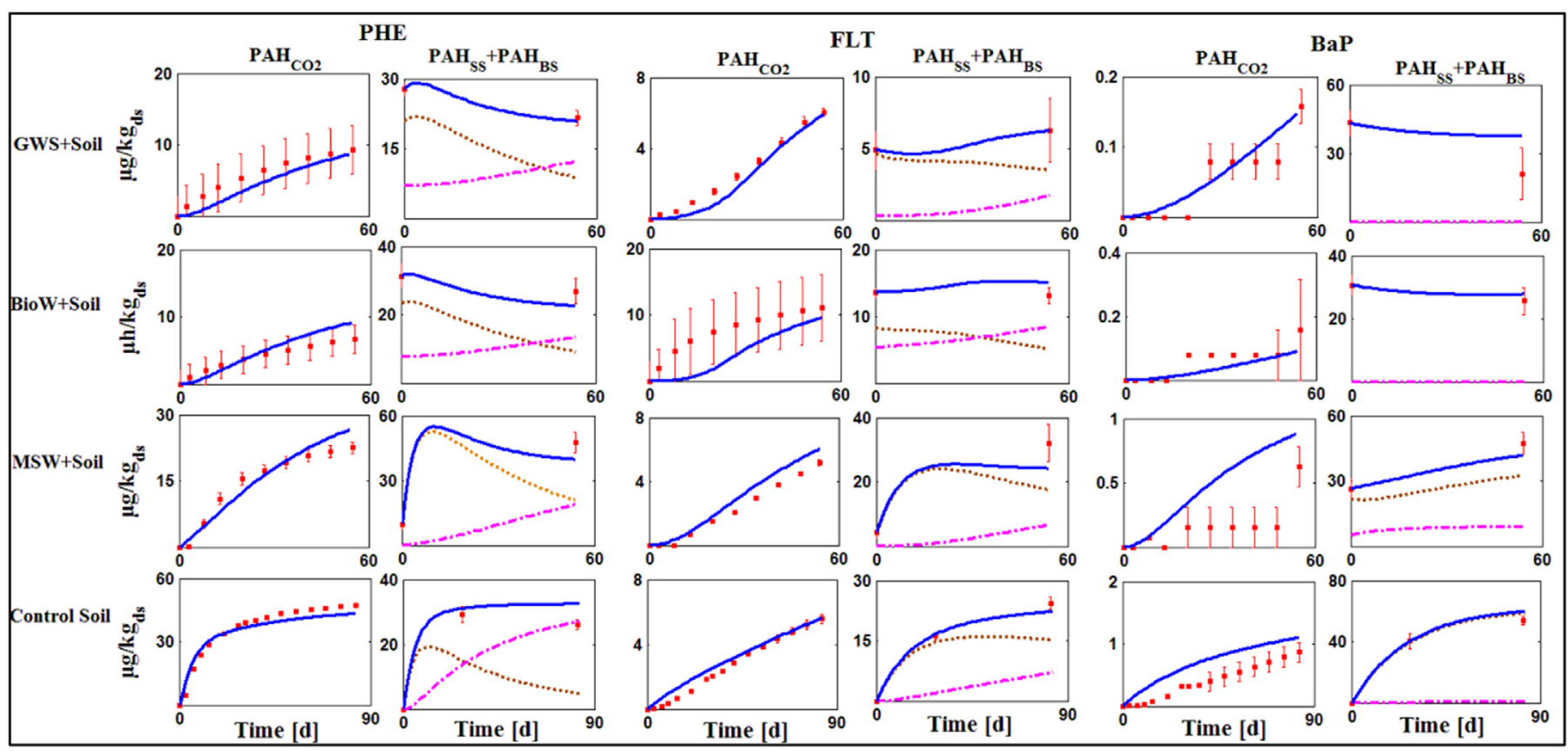

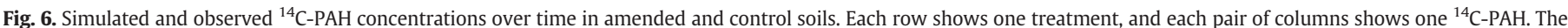

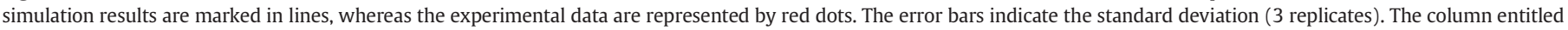

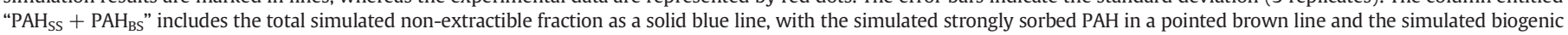
NER shown as a pink pointed dashed line. (For interpretation of the references to colour in this figure legend, the reader is referred to the web version of this article.) 
and affected FLT mineralization. Haudin et al. (2013) also noted the possible involvement of specific biomasses during FLT mineralization in GWS-soil mixtures, with a latency period (lag phase) being observed in the mineralization curves.

The NER fraction decreased or stayed constant in most treatments with GWS and BioW and highly increased for the MSW and soil treatments (Fig. 6). The simulated $\mathrm{PAH}_{\mathrm{SS}}$ decrease was always accompanied by an increase in the $\mathrm{PAH}_{\mathrm{BS}}$. The increased NER in the MSW was due to the increase in biogenic NER that was stimulated by the higher microbial biomass growth in this treatment (see Table A5). In fact, in the model, the microbial activity controls both mineralization and biogenic NER production (Eq. IX and X in Table A1). The biogenic productions of NER estimated by the model for PHE were in the following order: unamended soil $>$ MSW $>$ BioW $>$ GWS. This order was comparable to the order obtained for the mineralization of PHE. Similar results were also obtained for FLT, but for BAP, very little biogenic NER production was simulated because the rate of biogenic NER formation from PAH ${ }_{\text {MET }}$ $\left(\mathrm{k}_{\mathrm{MB}}\right)$ was much lower for this PAH. The difference between PAHs indicated that the biogenic NER production rates were lower for PAHs with a high number of benzene rings. However, this result of the simulations could not be confirmed with this experiment. Additional measurements for the biogenic NER fraction using the methods proposed by Nowak et al. (2013) could be used in the future.

The decrease in the adsorbed compartments $\left(\mathrm{PAH}_{\mathrm{CPWs}}+\mathrm{PAH}_{\mathrm{Ws}}\right.$ as shown in Figs. 6, A1, A2, and A3) with time was more pronounced in the following order: PHE $>$ FLT $>$ BAP due to the increase in the PAH hydrophobicity, which increased the adsorption onto soil and composts. On the final day, much less PAH was adsorbed for PHE than for FLT and BAP. For each PAH, the decrease in the adsorbed fractions was more marked in the following order: Soil $>$ MSW $>$ BioW-GWS. For the BAP, we even noted an increase in the adsorbed compartments in the BioW and GWS compartments. The adsorption of hydrophobic contaminants is higher on mature organic matter as shown by Aslam et al. (2013) and was much more marked on amended than on unamended soil. We obtained the inverse order relative to mineralization curves in which the soil and MSW treatments displayed more carbon mineralization. In all the treatments, the simulated $\mathrm{PAH}_{\mathrm{Ws}}$ compartment increased at the expense of the simulated "compost" compartment $\left(\mathrm{PAH}_{\mathrm{CPWS}}\right)$ that diminished. This effect was more marked for less hydrophobic PAHs such as PHE. These results were very well simulated with the model.

\subsection{Model sensitivity to the composition of non-extractible residues}

The impact of the initial conditions of the biogenic fraction for the total non-extractible residues on the model $\mathrm{PAH}_{\mathrm{CO} 2}$ output was evaluated. The initial values of the percentage of biogenic contribution to the total non-extractible residues could vary between 0 and $100 \%$. The $\mathrm{CO}_{2}$ mineralization at the end of the incubations is presented for PHE and BAP for both the GWS and MSW treatments in Fig. 7.

The results show that the simulated $\mathrm{PAH}_{\mathrm{CO} 2}$ at the end of the simulation periods is highly impacted by the initial values of the biogenic fraction. We found that the $\mathrm{PAH}_{\mathrm{CO} 2}$ emission increased when decreasing the initial contribution of biogenic NER for all the treatments. This result was related to the model hypothesis, which assumed that the amount of $\mathrm{PAH}$ strongly sorbed onto the soil matrix $\mathrm{PAH}_{\mathrm{ss}}$, (the NER physical fraction), which might become bio-accessible for the microorganisms following a desorption process (because $\mathrm{ksw} \neq 0$ ) in contrast to the NER biogenic fraction, or $\mathrm{PAH}_{\mathrm{BS}}$, that could not be remobilized (Kästner et al., 2014). The relative decrease of $\mathrm{PAH}_{\mathrm{CO} 2}$ between $0 \%$ and $100 \%$ of the biogenic residue showed the following order: BAP $\times$ GWS $>$ PHE $\times$ GWS $>$ BAP $\times$ MSW $>$ PHE $\times$ MSW. The impact of the biogenic NER initial fraction on the $\mathrm{CO}_{2}$ emissions was higher for the GWS treatment than for the MSW, suggesting that the model was less sensitive for the initial biogenic NER fraction with the MSW treatment. The compost GWS created more initial non-extractable residues $\left(\mathrm{PAH}_{\mathrm{BS}}+\mathrm{PAH}_{\mathrm{SS}}\right)$ than MSW for both PAHs (see Fig. A1) and thus, changes in the initial composition of PAH NER led to higher differences in the final PAH mineralization for the GWS. This result underlined the assumption about the significant role of the compost quality in the dissipation of PAH in the amended soil. The reliability of our assumption about the nonextractible residue distribution has not yet been fully assessed, and further validation is still needed in the future.

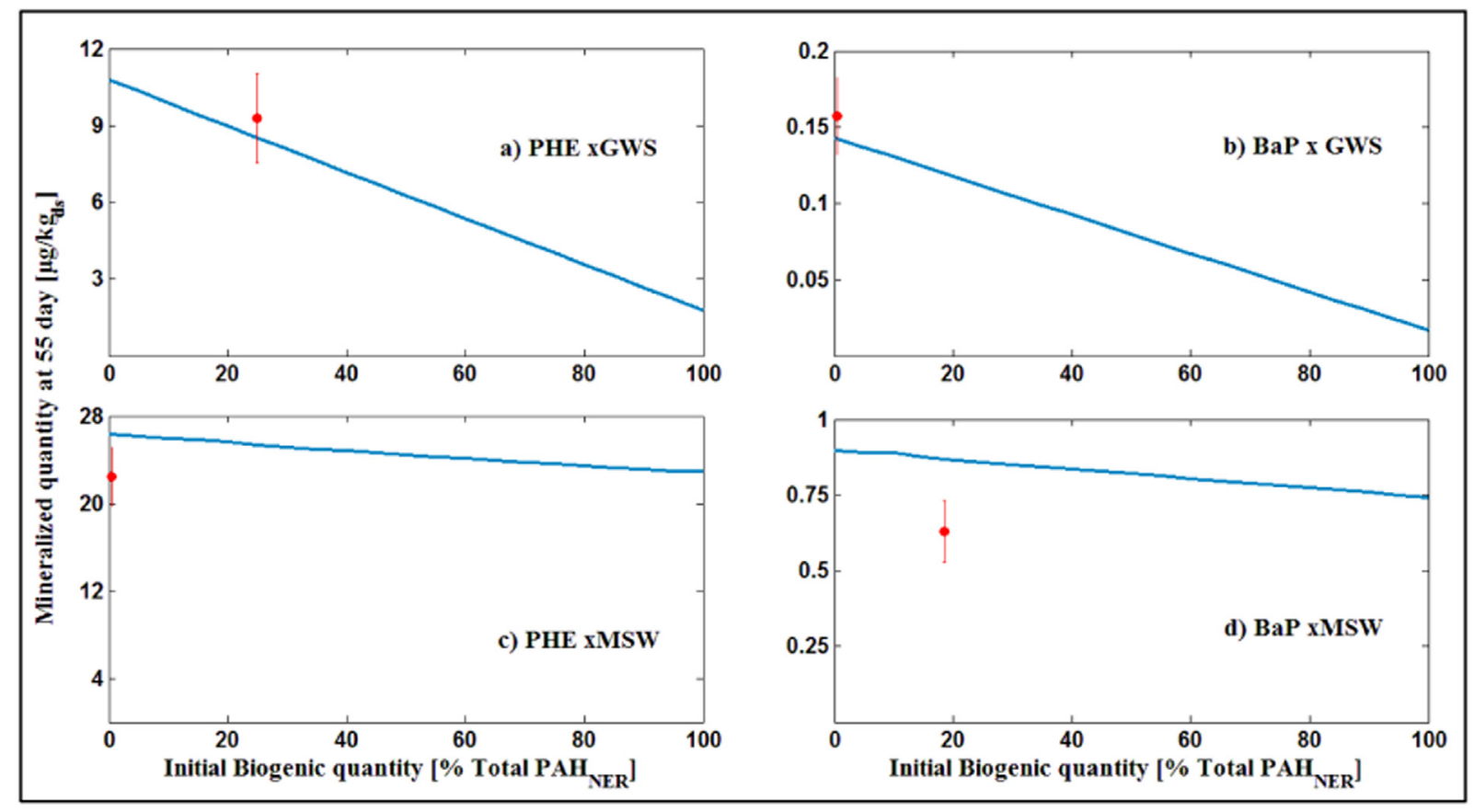

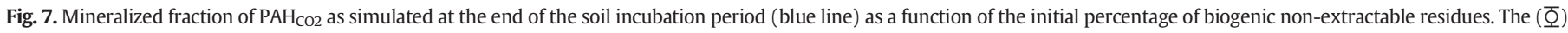

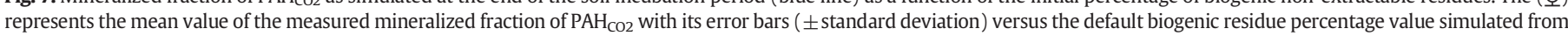
the compost incubation and reported in Table A5. (For interpretation of the references to colour in this figure legend, the reader is referred to the web version of this article.) 


\section{Conclusions}

The PAH-OC model was appropriate for describing the interactions between the primary physical, biological and biochemical processes that influenced the dissipation of PAHs included in the compost and after the compost application to soil under laboratory conditions. The most significant features of this model were to account for the organic matter characteristics of the applied compost, the production of nonextractible residues and the biodegradation pathway. A single parameter set for all the compost types was found to simulate the dynamics of PHE and BAP in the amended and non-amended soils to an adequate extent. For the FLT, this unique set of parameters could not be established, and a specific biomass biodegradation pathway had to be considered for mature composts. The modelling study confirmed that the processes occurring during composting, such as the non-extractable residue formation or the growth of a specific microbial biomass, had a strong impact on the fate of PAHs entering the soils through composts. During the compost incubations, the PAH dissipation was higher with mature composts because of the higher specific microbial activity, while in the incubations of soil amended with composts, the PAH dissipation was higher with the non-mature compost, partly because of the higher amount of available PAHs and the higher co-metabolic microbial activity. An experimental investigation to quantify the biogenic and physical proportion of the total non-extractible residues using recent methods reported in the literature is one of perspectives of this work. Further work should also be devoted to the application of the model in fields under long-term studies.

\section{Acknowledgements}

This research was financially supported by the French Environment and Energy Management Agency (ADEME) and the Environment and Agronomy division of the French National Institute for Agricultural Research (INRA). The experimental data were obtained during the $\mathrm{PhD}$ work of Christine Vergé-Leviel as financed by Veolia Environment.

\section{Appendix. Supplementary data}

Supplementary data to this article can be found online at https://doi. org/10.1016/j.scitotenv.2017.10.269.

\section{References}

Annabi, M., Bissonnais, Y. Le, Villio-poitrenaud, M. Le, Houot, S., 2011. Improvement of soi aggregate stability by repeated applications of organic amendments to a cultivated silty loam soil. Agric. Ecosyst. Environ. 144 (1), 382-389.

Aslam, S., Garnier, P., Rumpel, C., Parent, S.E., Benoit, P., 2013. Adsorption and desorption behavior of selected pesticides as influenced by decomposition of maize mulch. Chemosphere 91, 1447-1455.

Barriuso, E., Benoit, P., Dubus, I.G., 2008. Formation of pesticide nonextractable (bound) residues in soil: magnitude, controlling factors and reversibility. Environ. Sci. Technol. 42 (6), 1845-1854

Brändli, R.C., Bucheli, T.D., Kupper, T., Furrer, R., Stadelmann, F.X., Tarradellas, J., 2005. Persistent organic pollutants in source-separated compost and its feedstock materials-a review of field studies. J. Environ. Qual. 34 (3), 735-760.

Brimo, K., Garnier, P., Sun, S., Bertrand-krajewski, J., Cébron, A., Ouvrard, S., 2016. Using a Bayesian approach to improve and calibrate a dynamic model of polycyclic aromatic hydrocarbons degradation in an industrial contaminated soil. Environ. Pollut. 215, 27-37.

Cerniglia, C.E., 1997. Fungal metabolism of polycyclic aromatic hydrocarbons: past, present and future applications in bioremediation. J. Ind. Microbiol. Biotechnol. 19 (5-6), 324-333.
Chalhoub, M., Garnier, P., Coquet, Y., Mary, B., Lafolie, F., Houot, S., 2013. Increased nitrogen availability in soil after repeated compost applications: use of the PASTIS model to separate short and long-term effects. Soil Biol. Biochem. 65, 144-157.

Corbeels, M., Hofman, G., Van Cleemput, O., 1999. Simulation of net immobilization and mineralization in substrate-ammended soils by the NCsoil computer model. Biol. Fertil. Soils 28 (4), 422-430.

Francou, C., Linères, M., Derenne, S., Le Villio-Poitrenaud, M., Houot, S., 2008. Influence of green waste, biowaste and paper-cardboard initial ratios on organic matter transformations during composting. Bioresour. Technol. 99, 8926-8934.

Geng, C., Haudin, C.-S., Zhang, Y., Lashermes, G., Houot, S., Garnier, P., 2015. Modeling the release of organic contaminants during compost decomposition in soil. Chemosphere 119, 423-431.

Gevao, B., Jones, K.C., Semple, K.T., 2005. Formation and release of non-extractable ${ }^{14} \mathrm{C}$ Dicamba residues in soil under sterile and non-sterile regimes. Environ. Pollut. 133 (1), 17-24.

Goss, M.J., Tubeileh, A., Goorahoo, D., 2013. A review of the use of organic amendments and the risk to human health. Adv. Agron. 120, 275-379.

Haudin, C.S., Zhang, Y., Dumény, V., Lashermes, G., Bergheaud, V., Barriuso, E., et al., 2013. Fate of ${ }^{14} \mathrm{C}$-organic pollutant residues in composted sludge after application to soil. Chemosphere 92 (10), 1280-1285.

Houot, S., Verge-Leviel, C., Poitrenaud, M., 2012. Potential mineralization of various organic pollutants during composting. Pedosphere 22 (4), 536-543.

Iqbal, A., Garnier, P., Lashermes, G., Recous, S., 2014. A new equation to simulate the contact between soil and maize residues of different sizes during their decomposition. Biol. Fertil. Soils 50, 645-655.

Kästner, M., Nowak, K.M., Miltner, A., Trapp, S., Schäffer, A., 2014. Classification and modelling of non-extractable residue (NER) formation of xenobiotics in soil-a synthesis. Crit. Rev. Environ. Sci. Technol. 44 (19), 2107-2171.

Kästner, M., Streibich, S., Beyrer, M., Richnow, H.H., Fritsche, W., 1999. Formation of bound residues during microbial degradation of [14C]anthracene in soil. Appl. Environ. Microbiol. 65 (5), 1834-1842.

Lashermes, G., Zhang, Y., Houot, S., Steyer, J.P., Patureau, D., Barriuso, E., et al., 2013. Simulation of organic matter and pollutant evolution during composting: the COPcompost model. Environ. Qual. 42 (2), 361-372.

Mohammed, G., Trolard, F., Bourrié, G., Gillon, M., Tronc, D., Charron, F., 2016. A long-term data sequence (1960-2013) to analyse the sustainability of hay quality in irrigated permanent grasslands under climate change. Am. J. Agric. For. 4 (6), 140-151.

Morais, S.A., Delerue-Matos, C., Gabarrell, X., Blánquez, P., 2013. Multimedia fate modeling and comparative impact on freshwater ecosystems of pharmaceuticals from biosolids-amended soils. Chemosphere 93 (2), 252-262.

Nash, J.E., Sutcliffe, J.V., 1970. River flow forecasting through conceptual models part I - a discussion of principles. J. Hydrol. 10 (3), 282-290.

Nowak, K.M., Girardi, C. Miltner, A. Gehre, M., Schäffer, A., Kästner, M., 2013. Contribution of microorganisms to non-extractable residue formation during biodegradation of ibuprofen in soil. Sci. Total Environ. 445, 377-384.

Puglisi, E., Cappa, F., Fragoulis, G., Trevisan, M., Del, A.A.M., 2007. Bioavailability and degradation of phenanthrene in compost amended soils. Chemosphere 67 (3), 548-556.

Richnow, H.H., Annweiler, E., Koning, M., Lüth, J.C., Stegmann, R., Garms, C., et al., 2000. Tracing the transformation of labelled [1-13C]phenanthrene in a soil bioreactor. Environ. Pollut 108 (1), 91-101.

Tejada, M., Hernandez, M.T., Garcia, C., 2009. Soil restoration using composted plant residues: Effects on soil properties. Soil Tillage Res. 102 (1), 109-117.

Verge-Leviel, C., 2001. Les Micropolluants Organiques Dans les Composts D'origine Urbaine: Étude de Leur Devenir au Cours du Compostage et Biodisponibilité des Résidus Après Épandage des Composts au sol. Ph.D. Thesis. Institut National Agronomique Paris Grignon, France.

Vrugt, J.A., 2016. Markov chain Monte Carlo simulation using the DREAM software package: theory, concepts, and MATLAB implementation. Environ. Model. Softw. 75, 273-316.

Weissenfels, W.D., Beyer, M., Klein, J., 1990. Degradation of phenanthrene, fluorene and fluoranthene by pure bacterial cultures. Appl. Microbiol. Biotechnol. 32 (4), 479-484.

Wilcke, W., 2000. Polycyclic aromatic hydrocarbons (PAHs) in soil - a review. J. Plant Nutr. Soil Sci. 163 (3), 229-248.

Wild, S.R., Obbard, J.P. Munn, C.I., Berrow, M.L. Jones, K.C., 1991. The long-term persistence of polynuclear aromatic hydrocarbons (PAHs) in an agricultural soil amended with metal-contaminated sewage sludges. Sci. Total Environ. 101 (3), 235-253.

Wu, G., Kechavarzi, C., Li, X., Sui, H., Pollard, S.J.T., Coulon, F., 2013. Influence of mature compost amendment on total and bioavailable polycyclic aromatic hydrocarbons in contaminated soils. Chemosphere 90 (8), 2240-2246.

Zarfl, C., Klasmeier, J., Matthies, M., 2009. A conceptual model describing the fate of sulfadiazine and its metabolites observed in manure-amended soils. Chemosphere 77 (6), 720-726.

Zhang, Y., Lashermes, G., Houot, S., Doublet, J., Steyer, J.P., Zhu, Y.G., et al., 2012. Modelling of organic matter dynamics during the composting process. Waste Manag. 32 (1), $19-30$. 